\title{
Xylem Anatomical Study in Diverse Capsicum sp. Accessions, Implication to Drought Tolerance
}

\author{
Carla GUIJARRO-REAL ${ }^{1)}$, Rosa V. MOLINA ${ }^{2)}$, Teresa PÉREZ-DOMINGO ${ }^{1)}$, Ana M. RIBES-MOYA ${ }^{1)}$, Adrián \\ RODRÍGUEZ-BURRUEZO ${ }^{{ }^{*} \text {, }}$, Ana M. FITA ${ }^{1)}$
1)Institute COMAV and (2)Plant Production Department, ${ }^{1,2)}$ Universitat Politècnica de València, Camino de Vera s/n, 46022, Valencia, Spain. \\ ${ }^{*}$ Coresponding author, e-mail: anfifer@btc.upv.es
}

Bulletin UASVM Horticulture 71(2) / 2014

Print ISSN 1843-5254, Electronic ISSN 1843-5394

DOI:10.15835/buasvmcn-hort:10676

\begin{abstract}
Drought is a limiting factor for plant survival and food production. Plants have developed various strategies in response to this stress. The immediate response to drought is the closure of the stomata. However, it prevents the transpiration and the photosynthesis. From the point of view of crops, it is interesting the ability of the plants to keep photosynthesizing under drought. Leaf water content is affected by the difference among leaf and soil water potentials ( $\Psi_{\text {leaf }}-\Psi_{\mathrm{h}}$ ) and by the xylem-specific hydraulic conductivity (Ks). It has been hypothesized that the number and diameter of the xylem vessels would affect the drought tolerance. In this experiment the influence of the xylem anatomy in the tolerance to water stress of three Capsicum sp accessions: Bol 58, Piquillo, Chimayo was studied. Plants were grown in plastic pots filled with soil:sand mixture in a glasshouse at UPV, during spring season. Two different treatments were used in the assay: normal irrigation and restricted irrigation (50\% less irrigated than the control). Three and a half months after transplantation plants were harvested; roots, stems and fruits were weighted. Portions of the stem bases were fixed in FPA and rehydrated for the analysis of the xylem total area. Material was sectioned with a freezing microtome and dyed with phloroglucinol. Vessel element area was calculated with Autocad software. There were significant differences of biomass among genotypes and treatments. Piquillo showed lowest reduction of biomass under stress. The genotypes studied showed differences in the xylem structure. In addition, there were changes in the vessel diameter pattern from control to drought conditions. Generally, plants grown under water deficit reduce the number of bigger vessels $\left(>7500 \mu \mathrm{m}^{2}\right)$. Chimayo was the accession with bigger vessels, in normal and stress conditions, whereas Piquillo had smaller vessels. Therefore results showed a negative correlation between vessel size and production under stress conditions. Big vessels are prone to cavitation and a high proportion of small vessel may contribute to maintain Ks without collapse risk.
\end{abstract}

Keywords: hydraulic potential, pepper, root, water stress

\section{INTRODUCTION}

Drought is an important constraint for plant survival and food production. The immediate response of plants to drought is the closure of the stomata. However, it prevents the transpiration and the photosynthesis. Plants adapted to arid conditions have developed different strategies to overcome this problem such as acquiring more water through deep root systems, increasing the osmolarity, suffering partial defoliation or changing the leaf morphology. From the point of view of crops, it would be interesting any strategy which permits the plants to keep photosynthesizing under drought, and then, keep producing.

Stomata aperture under drought depends mostly on the leaf water content, which in turn is affected by the difference among leaf and soil water potentials $\left(\Psi_{\text {leaf }}-\Psi_{\mathrm{h}}\right)$ and by the xylemspecific hydraulic conductivity (Ks). Under water stress, leaf water potential $\left(\Psi_{\text {leaf }}\right)$ decreases and a more negative water potential in the xylem appear, in an attempt to enhance water uptake to leaves. Consequently, a tension appears in the xylem which increases the possibility of cavitation 
(Sperry and Tyree 1988; Ogasa et al. 2014). Cavitation can compromise the integrity of plants. It produces an interruption in the water column that increases the hydraulic resistance and limits the water flow (Tyree and Ewers 1991; Bauerle et al 2011). Cavitation can be avoided closing the stomata (Tyree and Sperry 1988; Jones and Sutherland 1991), losing some leaves (Meinzer and Grants 1990; Vilagrosa et al. 2003) but also reducing the number and/or diameter of the big vessels. The two first options are not a solution for crops since reduction of photosynthesis and partial defoliation limits yield. However, the third option could be a nice solution. Taking into account the importance of the xylem anatomy in the hydraulic conductance, it has been hypothesized that a reduction in the number of big vessels or the diameter of those can be an adaptation which improves the tolerance to drought (e.g. Lovisolo and Schubert 1998; Beikircher and Mayr 2009; Taryn L. Bauerle et al 2011).

The objective of this work was to study the influence of the xylem anatomy in the tolerance to water stress in three Capsicum sp accessions: Bol 58, Piquillo, Chimayo.

\section{MATERIALS AND METHODS}

This assay studied the effect of water availability in xylem anatomy, in Capsicum sp. Plants belonging to three accessions, Bol 58 (C. baccatum L.), Piquillo (C. annuum L.) and Chimayo (C.annuum L.) were used. Seeds were germinated in saturating humidity conditions until the cotyledons were released and then, they were transplanted to plastic pots filled with soil:sand mixture for growing, in a glasshouse at UPV, Spain, during spring season. Plants were grown under two different treatments i) Normal (N) which consisted in irrigating the plants as in a conventional culture and ii) drought (S) which consisted in irrigating with the half amount of water than the normal treatment. Four plants of each accession were grown under each treatment.

After three and a half months growing in those conditions, plants were harvested. The biomass production was obtained as the sum of the partial fresh weights of the different parts of the plant including roots. Portions of $2 \mathrm{~cm}$ long of the stem bases were fixed in FPA (formaline: propionic acid: ethanol 1:1:18) and reserved for the xylem anatomy study. In the moment of the analysis, samples were rehydrated with successive ethanol washes, $100 \%$ for $24 \mathrm{~h}$ plus $70 \%, 50 \%$, $20 \%$ water dilutions for 10 minutes each and a final wash in water. Transversal sections of the stems were cut with a freezing microtome, dyed with phloroglucinol-clorhidric acid and analyzed (Figure 1). The number of big and small vessel elements and the area was calculated with Autocad software.

Finally, an analysis of variance (ANOVA) was performed.
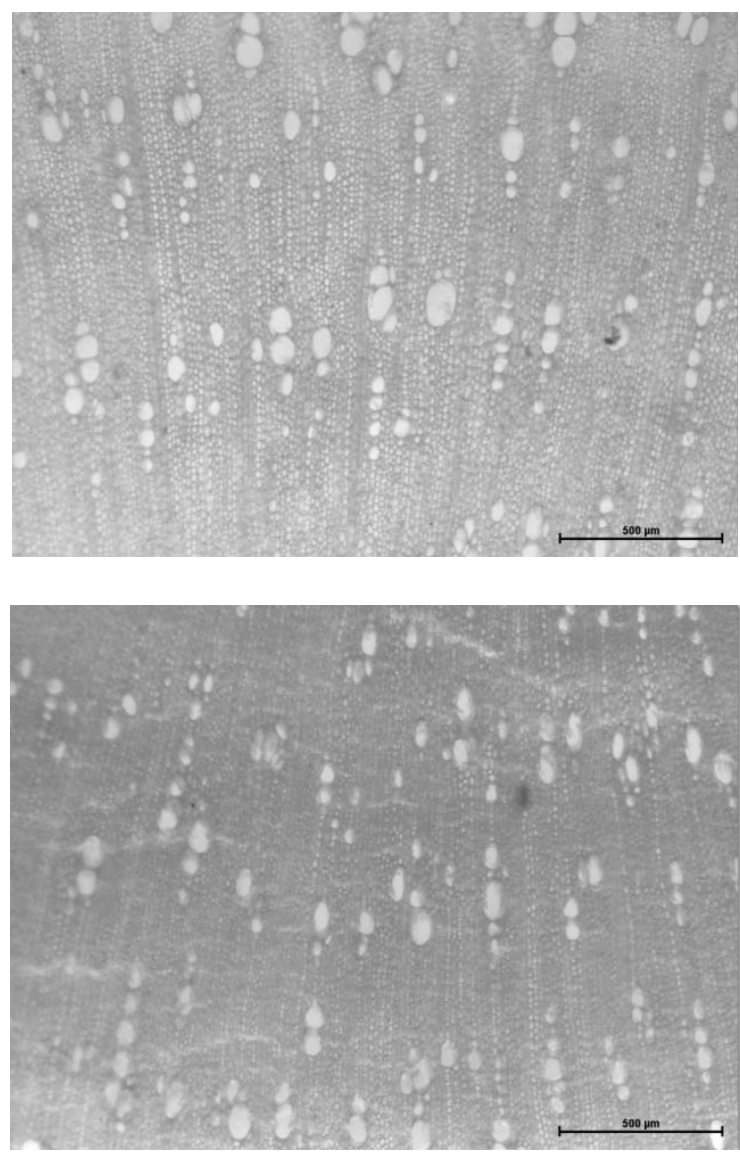

Fig. 1. Transversal sections from the base of the stem in Piquillo, for a) control and b) drought conditions.

\section{RESULTS AND DISCUSSION}

Results showed a significant reduction in biomass between $6-40 \%$ in treatment S (P-value 0.0042 when fruits were not considered; P-value 0.0172 when they were considered). Furthermore, there were significant differences among accessions. Piquillo was the genotype with a better response to drought conditions, with a reduction of 5,6\% not including the weight of the 


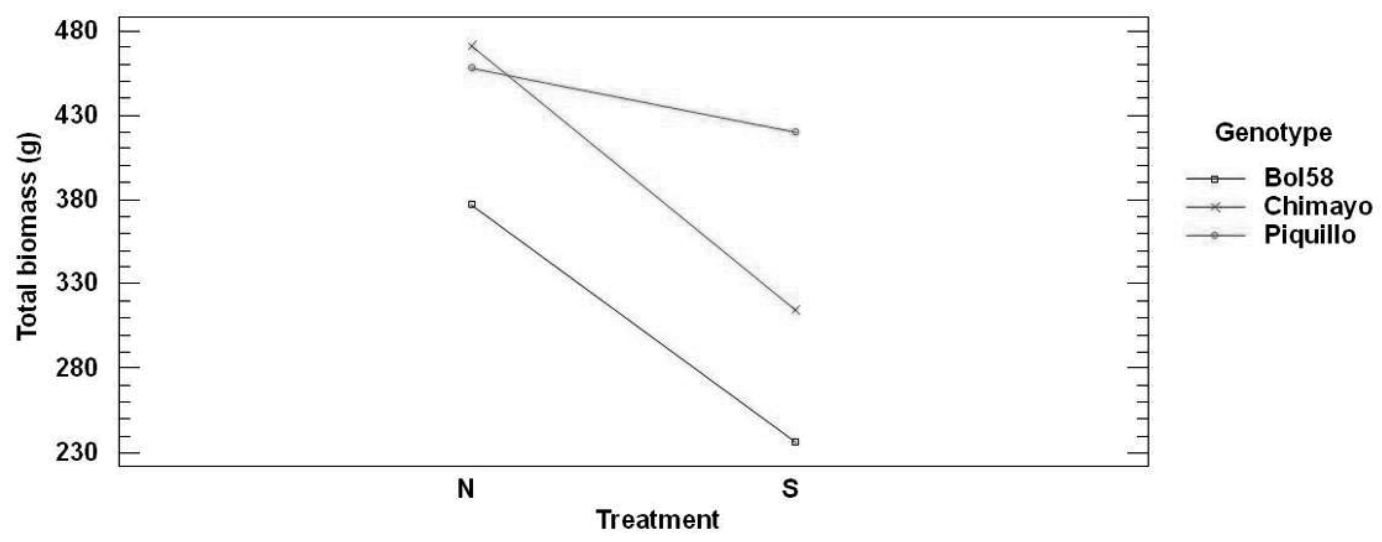

Fig. 2. Total biomass in the different genotypes and treatments, drought $(\mathrm{S})$ and normal conditions $(\mathrm{N})$.

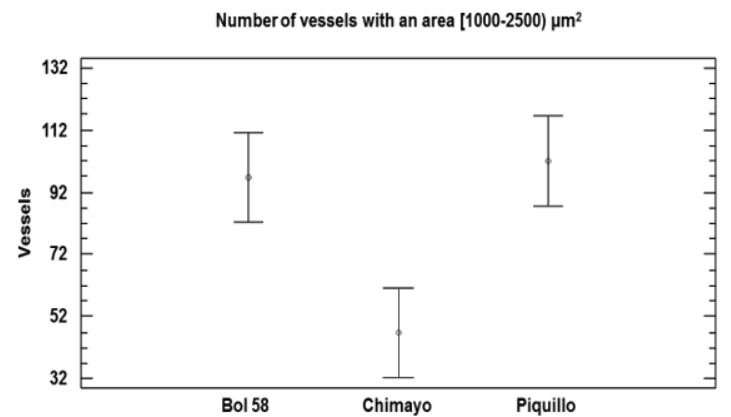

a)

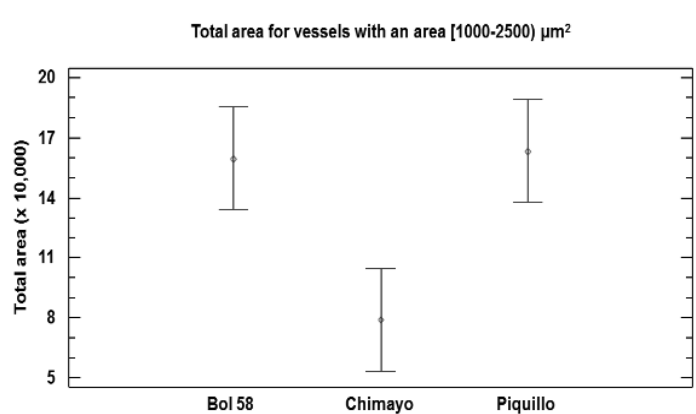

b)

Fig. 3. Changes among genotypes for vessels from $1000 \mu \mathrm{m}^{2}$ to $2500 \mu \mathrm{m}^{2}$.

a) Differences in the number of vessels among genotypes and b) differences in the total area occupied in the xylem.

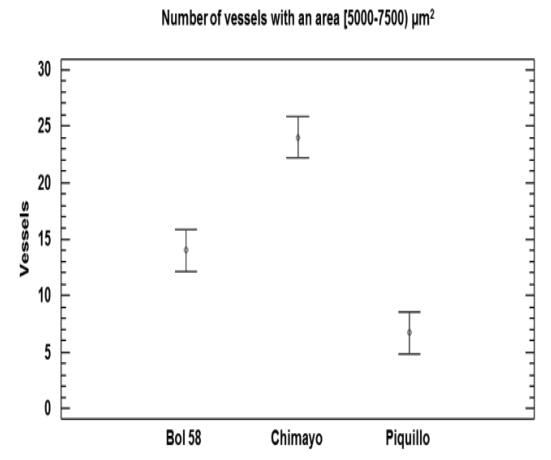

a)

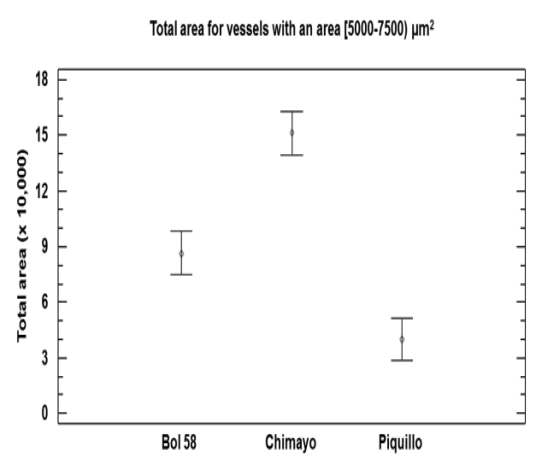

b)

Fig. 4. Number and total area occupied for vessels from $5000 \mu \mathrm{m}^{2}$ to $7500 \mu \mathrm{m}^{2}$.

a) Differences in the number of vessels among genotypes and

b) differences in the total area occupied in the xylem. 


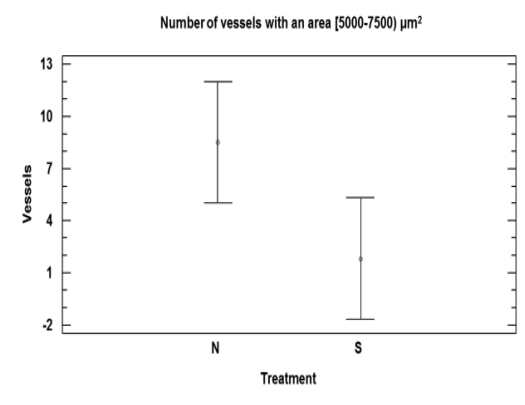

a)

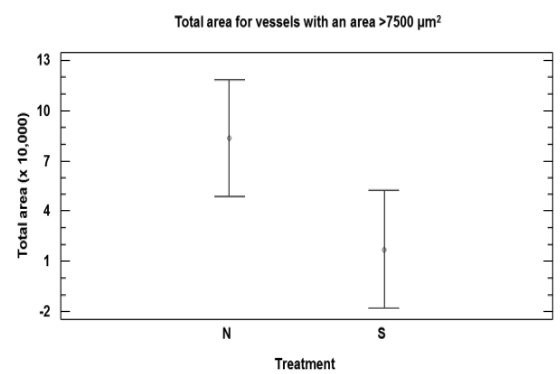

b)

Fig. 5. Number and total area occupied for vessels $>7500 \mu \mathrm{m} 2$. a) Differences in the number of vessels among treatments and b) differences in the total area occupied in the xylem. For the biggest vessels appeared significant differences considering the treatment applied, normal or drought, for the three accessions.

fruits; Bol 58 and Chimayo reduced their biomass near to $30 \%$ in those conditions (Figure 2).

The analysis of the xylem structure showed differences among genotype and treatment. When smaller vessels where considered (1000$2500 \mu \mathrm{m}^{2}$ ), significant differences in number and total area where found among genotypes (Figure 3 ). Thus, Chimayo was the accession with fewer small vessels whereas that Bol 58 and Piquillo showed similar results. Significant differences among treatment were not found. For vessels with an area from $5000 \mu \mathrm{m}^{2}$ to $7500 \mu \mathrm{m}^{2}$, differences were among genotype, being Chimayo the accession with a greater number and total area (Figure 4). However, when bigger vessels were analyzed $\left(>7500 \mu \mathrm{m}^{2}\right)$, significant differences appeared among treatment (Figure 5). For the three genotypes, the exposition to drought conditions resulted in a reduction of the number of those vessels and the total area occupied by them; Piquillo had less proportion of bigger vessels. Finally, significant differences were not found for the number of vessels included in the range of 2500-5000 $\mathrm{m}^{2}$, among genotype or treatment (P-value 0.3122 and P-value 0.5452, respectively).

\section{CONCLUSIONS}

The genotypes studied showed differences in the total biomass production, both among accessions and treatment. There was a general trend to reduce the biomass production when plants were subjected to drought conditions. However, the effect that water stress produced to the plant varied from one genotype to another. This response could help the producer to choose the best variety according to the climate conditions.

On the other hand, the pattern of vessels distribution and xylem structure changed for the different genotypes and conditions. Although the number and total area occupied by the smaller vessels varied for the accessions, there were a general response to drought. Thus, the number of bigger vessels $\left(>7500 \mu \mathrm{m}^{2}\right)$ was reduced under stress conditions whereas the proportion of small vessels increased.

In addition, a negative correlation between vessel size and total biomass appeared when water was restricted. In fact, the proportion of bigger vessels in Piquillo was the lowest and this accession reduced the production less than others. As conclusion, when plants are growing under water stress, changes in the xylem anatomy can occur. Increasing the proportion of small vessels may contribute to maintain Ks preventing collapse risk, without compromising plant growth.

\section{REFERENCES}

1. Beikircher B, Mayr S (2009). Intraspecific differences in drought tolerance and acclimation in hydraulics of Ligustrum vulgare and Viburnum lantana. Tree Physiol 29:765-775

2. Gonçalves B, Correia C, Silva A, Bacelar E, Santos A, Ferreira H, Moutinho-Pereira J (2007). Variation in xylem structure and function in roots and stems of scionrootstock combinations of sweet cherry tree (Prunus avium L.). Trees 21:121-130

3. Jones HG, Sutherland RA (1991). Stomatal control of xylem embolism. Plant Cell Environ 14:607-612 
4. Lovisolo C, Schubert A (1998). Effects of water stress on vessel size and xylem hydraulic conductivity in Vitis vinifera L. J Exp Bot 49:693-700

5. Ogasa M, Miki NH, Okamoto M, Yamanaka N, Yoshikawa K (2014). Water loss regulation to soil drought associated with xylem vulnerability to cavitation in temperate ringporous and diffuse-porous tree seedlings. Trees 28:461469

6. Meinzer FC, Grants DA (1990). Stomatal and hydraulic conductance in growing sugarcane: stomatal adjustment to water transport capacity. Plant Cell Environ 13:383388
7. Sperry JS, Tyree MT (1988). Mechanism of water stressinduced xylem embolism. Plant Physiol 88:581-587

8. Bauerle TL, Centinari M, Bauerle WL (2011). Shifts in xylem vessel diameter and embolisms in grafted apple trees of differing rootstock growth potential in response to drought. Planta 234:1045-1054

9. Tyree MT, Ewers FW (1991). The hydraulic architecture of trees and other woody plants. New Phytol 119:345-360

10. Vilagrosa A, Bellot J, Vallejo VR, Gil-Pelegrin E (2003). Cavitation, stomatal conductance, and leaf dieback in seedlings of two cooccurring Mediterranean shrubs during an intense drought. J Exp Bot 54:2015-2024 